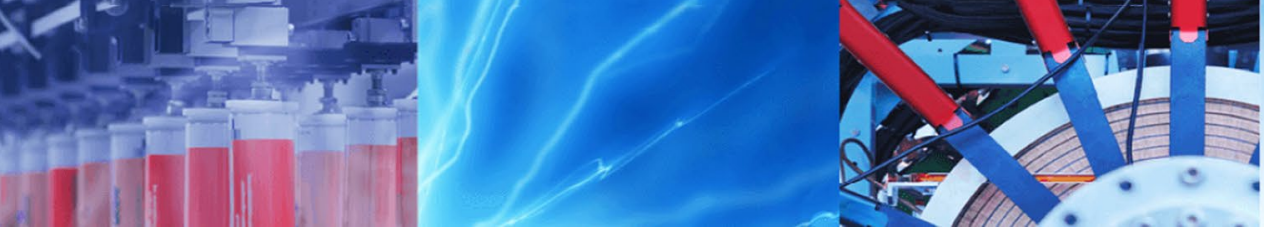

Research Article

\title{
Fabrication and dry sliding wear study of Al6061/mussel-shell particulate composites
}

\author{
Surendra Kumar Dwiwedi ${ }^{1}$. Ashok Kumar Srivastava ${ }^{2} \cdot$ Manoj Chopkar $^{1}$
}

(c) Springer Nature Switzerland AG 2019

\begin{abstract}
Considering the combination of the good physical-mechanical property of mussel shell (MS) and its bulk availability at low processing cost, in present work an attempt has been made to use it as reinforcing particulate material for fabricating Al6061/MS composite through stir casting route. The composite is fabricated with 2, 4, 6, 8 and 10 weight percent (wt\%) of mussel shell reinforcement. Microstructural characterization revealed the fair distribution of particles in the matrix. Fabricated matrix with $6 \mathrm{wt} \%$ mussel shell has shown the maximum hardness and wear resistance beyond that adverse effect has been quantified. Linear regression analysis helped in establishing the relationship between independent variables of load, sliding distance and reinforcement volume in wt\% to calculate wear loss and wear rate. Analysis of variance helped to confirmed that incorporation of MS particulates significantly contributing to the improvement of the wear properties.
\end{abstract}

Keywords Al6061 · Mussel shell · Wear · Stir casting · Waste

\section{Introduction}

Aluminium-metal matrix composites (AMCs) have been advocated as the potential candidates for application in automobile industry owing to their superior physicalcum-mechanical properties over unreinforced alloys [1, 2]. The most preferred matrix material is Al6061 due to its moderate strength and lightweight potential. In spite of several favourable properties, it shows the poor tribological properties. With the aim of overshadowing the poor wear properties, soft matrix alloys are reinforced with hard ceramic particulates to increase the hardness of material $[3,4]$. The choice of particulate reinforcement produces isotropic composites [5]. The commonly used ceramic reinforcements are $\mathrm{SiC} \mathrm{Al}_{2} \mathrm{O}_{3}, \mathrm{TiC}$, and $\mathrm{B}_{4} \mathrm{C}[6,7]$. However, these ceramic reinforcement materials suffer the disadvantages of undergoing reaction with aluminium alloy constituents, forming a brittle layer at the particle-matrix interface, high density and high raw-material cost $[6,8,9]$.
It will be thus justified to employ low dense and inexpensive reinforcements for producing lightweight automobile components like brake pads, brake caliper pins, levers where the wear of material is a predominant process. In recent past, natural minerals and waste by-products from agriculture, poultry, thermal power plants, and marine environment are attracting researcher and being encouraged as alternative reinforcing material due to their bulk availability at low processing cost, lightweight properties and opportunity of in situ synthesis of reinforcement [10, 11]. Fly ash [12], rice husk ash [13], chicken eggshell [14], mineral calcium carbonate [15] and many more, have been investigated for their suitability as reinforcements. Calcium carbonate occurs naturally and mostly found in biological sources, for instance, eggshell, snail shell, seashells, clams and the freshwater mussel shell $[16,17]$. A mussel shell is a hard-protecting outer layer animal body part which habitats in freshwater. The shell is empty when the animal has died and its soft parts have been either decomposed or

$\triangle$ Surendra Kumar Dwiwedi, surendra.dwiwedi@opju.ac.in | ${ }^{1}$ Metallurgical Department, National Institute of Technology Raipur (CG), Raipur, India. ${ }^{2}$ Metallurgy and Materials Engineering Department, O P Jindal University Raigarh (CG), Raigarh, India.

SN Applied Sciences (2019) 1:721 | https://doi.org/10.1007/s42452-019-0767-y 
eaten by another animal. Mussel shell is considered as biowaste and mostly remains unnoticed; however, researchers have highlighted its potential use as adsorbent, catalyst, orthopedic biomaterial, construction and recyclable material [18-20]. Xiong et al. [21] assessed the capacity of mussel shell for phosphate removal from solutions. $\mathrm{Hu}$ et al. [22] carried out transesterification of Chinese tallow oil for biodiesel synthesis using freshwater mussel shell derived catalyst and reused it more than seven times without serious deactivation. Ez-zaki and co-worker [23] have shown the manufacturing of eco-friendly building material mortar from waste mussel shell and glass by partially replacing the sand. It is reported that incorporation of these waste materials improved the mortar in terms of thermal insulation, compressive strength, and resistance against chloride attack. Lv et al. [24] carried out microstructural and mechanical characterization of freshwater mussel shell. The mechanical properties were characterized by nano-indentation and three-point bending test. The fracture toughness of mussel shell was reported as $0.87 \mathrm{MPa} \mathrm{m}^{1 / 2}$ while that of natural calcite is $0.2 \mathrm{MPa} \mathrm{m}^{1 / 2}$. The improvement in mechanical property is cited due to the presence of organic matrix in the prismatic layer of mussel shell which helps in crack arresting.

On the basis of reported literature, it can be mentioned that the mussel shell is a versatile material of great potential. However, its usefulness and adaptability in engineering applications are not exposed satisfactorily although, it is harmonized with excellent mechanical and physical properties. Such an interesting aspect of bio-waste mussel shell motivated us to carry out the present study with the aim of waste management and value creation. Therefore, the present work aims to fabricate, characterize and study the wear behaviour of Al6061/Mussel shell composites using mussel shell as reinforcement. Further, an attempt has been made using Analysis of variance (ANOVA) to evaluate whether the incorporation of MS particulates affected wear properties of fabricated composite significantly. Regression analysis is also conducted to establish a relationship among independent variables affecting the wear performance of composites.

\section{Materials and method}

Al6061-T6 grade alloy was used as matrix while mussel shell powder was used as reinforcement material. Aluminium alloy was purchased from Perfect Metal works Corporation (PMC) Bengaluru, India. Freshwater mussel shell wastes were collected from the banks of Arpa river in Bilaspur, India. Figure 1 portrays the mussel shell into its crushed and powder form. The elemental composition of the alloy is given in Table 1. Mussel shell contains biomineralized $\mathrm{CaCO}_{3}$ as the majority of its chemical composition by weight $[25,26]$. The stir casting process is adopted to fabricate the composites considering its economic advantage, simplicity and flexibility with the selection of materials and processing parameters, overall production of the low-cost composite are targeted. Collected mussel shells were washed with fresh water to remove any adhered foreign particles, followed by boiling in water for $30 \mathrm{~min}$. Thoroughly cleaned shells were allowed to dry in sunlight for more than 2 weeks. Sufficiently dried shells were then mechanically crushed before subjected to pulverization using disc pulverizer machine. The powder size analysis was carried out in vibratory sieve shaker machine as per standards and particle size of 100-120 microns was used as reinforcement particulates. Before starting
Fig. 1 a Crushed mussel shells and $\mathbf{b}$ pulverised mussel shells

Table 1 Elemental composition of Al6061 by weight percentage

\section{SN Applied Sciences}

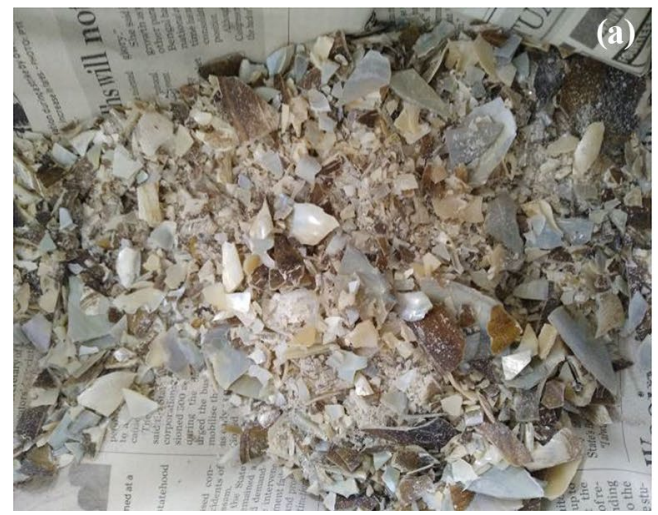

(b)

\begin{tabular}{llllllllll}
\hline Element & $\mathrm{Si}$ & $\mathrm{Fe}$ & $\mathrm{Cu}$ & $\mathrm{Mn}$ & $\mathrm{Mg}$ & $\mathrm{Cr}$ & $\mathrm{Zn}$ & $\mathrm{Ti}$ & $\mathrm{Al}$ \\
\hline Percentage & 0.663 & 0.543 & 0.347 & 0.058 & 0.881 & 0.273 & 0.069 & 0.052 & Balance \\
\hline
\end{tabular}


the fabrication process, all the melt-contacting surfaces were applied to protecting the layer of high-temperature nonsticky paint. Addition of reinforcing particles was expressed in weight percentage, defined as the ratio of the weight of reinforcing particles to the weight of the alloy matrix. Alloy is subjected to heating and melting at $750^{\circ} \mathrm{C}$ while particulate shell powder is heated in an oven at $150^{\circ} \mathrm{C}$ for $1 \mathrm{~h}$ to remove all the absorbed moisture. The preheated powder is incorporated carefully in a controlled manner to the melt vortex created by the stirrer which is set to rotate at $500 \mathrm{rpm}$ for $10 \mathrm{~min}$. Afterward, the molten alloy is cast in a preheated steel mould to produce the cast bars of $200 \mathrm{~mm}$ length and $20 \mathrm{~mm}$ diameter. The same methodology was adopted for the fabrication of all composites including melting and casting of unreinforced alloy matrix. Specimens for various tests were collected from the central part of the cast after machining.

Microstructural Studies were executed on composites using standard metallographic process. The cylindrical samples were machined out from the cast composite, measuring $12 \mathrm{~mm}$ diameter and $10 \mathrm{~mm}$ height. The samples were finely polished using $1-5$ grade emery paper. Afterward, it is subjected to velvet and diamond polishing, followed by etching it for $30 \mathrm{~s}$ in Keller's reagent. The optical micrographs were captured using Axiocam ERc5 s ZEISS made an optical microscope. Zeiss Evo MA-18 Scanning Electron Microscope (SEM) and Oxford Inca Energy Dispersive X-ray (EDX) was used to confirm the elemental presence. The experimental density of fabricated composites has been measured using Archimedes principle while theoretical density was calculated by the rule of mixture theory. The mass of the composite sample was first weighed using an electronic balance of accuracy $\pm 0.001 \mathrm{~g}$. The measuring cylinder is filled with $50 \mathrm{ml}$ of tap water and change in volume of water was recorded when the composite sample was immersed in it. Density is then calculated as the ratio of mass to change in volume of water. Further, the experimental and theoretical values were compared to observe the porosity percentage. The ASTM E18 standard Rockwell hardness test was carried out at room temperature conditions on polished test specimens measuring diameter and height as $12 \mathrm{~mm}$ and $10 \mathrm{~mm}$ respectively. The test evaluated the hardness of matrix alloy and different composites using a steel ball indenter (diameter $\phi=1.588 \mathrm{~mm}$ ) at an applied load of $100 \mathrm{~kg}$ and dwell period of $5 \mathrm{~s}$. Each result is taken as the average of five attempts at different locations. Standard ASTM G99 dry wear sliding test for composites was performed on DUCOM TR20 computerized pin-on-disc wear testing machine. The samples utilized were cylindrical solid body measuring $10 \mathrm{~mm}$ diameter and $25 \mathrm{~mm}$ height having a smooth surface finish. The counter surface was employed with 220 grit SiC emery paper, firmly clamped to the steel disc using a ring holder arrangement. The sliding test was carried out under ambient conditions for three different loads of $10 \mathrm{~N}, 20 \mathrm{~N}$ and $30 \mathrm{~N}$ while constant test parameters of $300 \mathrm{rpm}$, track diameter of $65 \mathrm{~mm}$ and rotation time of $120 \mathrm{~s}$ was maintained. The wear loss was calculated as height loss in microns, further converted to volume loss $\left(\mathrm{mm}^{3}\right)$ by multiplying cross-section area of the sample with height loss. Wear rate (W) was calculated as the ratio of volume loss to the sliding distance. Coefficient of friction (CoF) was graphed directly as output from the computer screen while graphs of cumulative volume loss (V) and wear rate (W) were plotted against sliding distance. Scanning electron microscopy equipped with energy dispersive spectroscopy characterization was performed on wear tacks for an insight understanding of the wear mechanism took place. Determination of critical transition load, where the behavior of material changes from mild to severe wear due to increased plastic deformation, is interestingly important. It has been demonstrated that various wear mechanisms may act together and the dominance of a particular mechanism depends upon applied load [27]. Therefore, wear performance is precisely measured as a function of load, sliding distance and reinforcement weight percentage. Regression analysis and ANOVA is carried out using MINITAB 17 software.

\section{Results and discussions}

\subsection{XRD of mussel shell}

The X-ray diffractogram of pulverized mussel shells which confirms the presence of calcite along with its polymorph aragonite formed due to bio-mineralization of $\mathrm{CaCO}_{3}$ has been demonstrated in Fig. 2. The observed peaks were analyzed using Panalytical-High Score plus version 3.0e software. It has been reported that the shell's core structure is made of calcite while aragonite is present as building blocks of the structure $[20,24,25]$. Other peaks are accounted due to the presence of impurities in the outer part of the shell, mostly in the form of quartz $\left(\mathrm{SiO}_{2}\right)$ and possibly Larnite $\left(\mathrm{Ca}_{2} \mathrm{SiO}_{4}\right)$ and Rankinite $\left(\mathrm{Ca}_{3} \mathrm{Si}_{2} \mathrm{O}_{7}\right)$.

\subsection{Microstructural study}

Figure 3a and $b$ displays the SEM micrograph of alloy 6061 and EDX respectively, confirming the presence of $\mathrm{Al}, \mathrm{Mg}$ and Si while Fig. $3 \mathrm{C}$ and d represents the SEM micrograph of $8 \mathrm{wt} \% \mathrm{MS}$ composite and its EDX respectively, highlighting the presence of calcium in the form of calcium carbonate and Iron ( $\mathrm{Fe}$ ) may have diffused during fabrication. SEM micrograph of composite also reveals agglomeration of particles and porosity. 


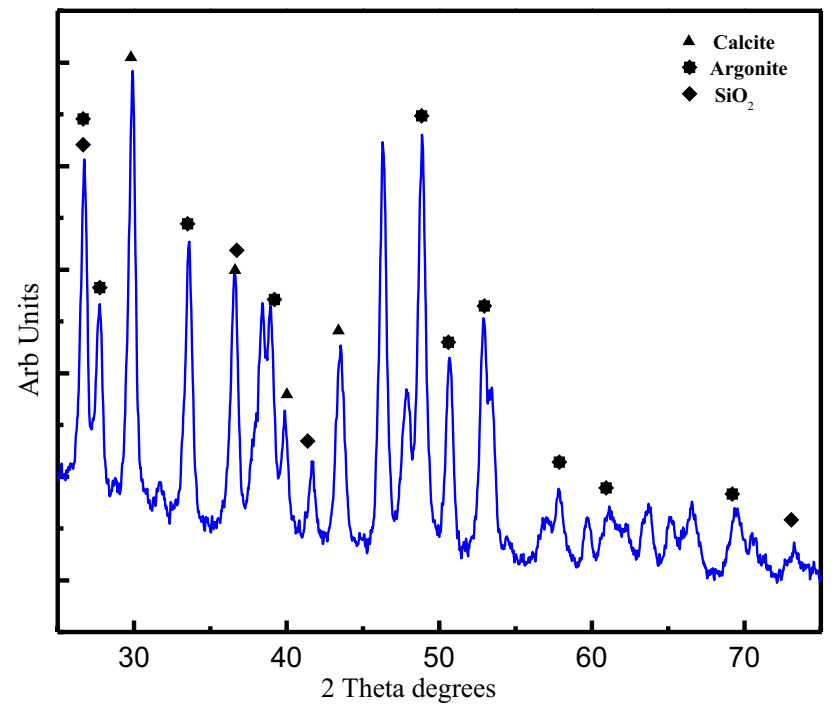

Fig. 2 X-ray diffractogram of mussel shell powder

Optical micrographs of different composites have been captured to study the distribution of reinforcing particles in the matrix, the same is illustrated in Fig. 4. It is evident from micrograph that the reinforcing particles are fairly distributed in the matrix. The $6 \mathrm{wt} \%$ composites show relatively more filler content of particles while $10 \mathrm{wt} \%$ composite shows more intent of agglomeration of particles along grain boundaries.

\subsection{Density}

This section discusses the comparison of the experimental and theoretical densities of fabricated composites. The density of mussel shell is calculated experimentally as $2.68 \mathrm{~g} / \mathrm{cc}$ while that of the alloy is $2.71 \mathrm{~g} / \mathrm{cc}$. Figure 5 portrays the variation of density of composite with an increasing weight percentage of MS particles. It is noticed that the density of composites is lower than that of the base matrix alloy. Moreover, the density decreases with an increase in particle content which can be mentioned to the reasons firstly, the use of low-density MS particles and secondly, increases in the intent of porosity. The sharp decrease in density after $6 \mathrm{wt} \%$ is mainly due to the increase in viscosity of the melt, thereby inviting entrapment of surrounding gases in large volume and subsequent increase in porosity $[28,29]$.
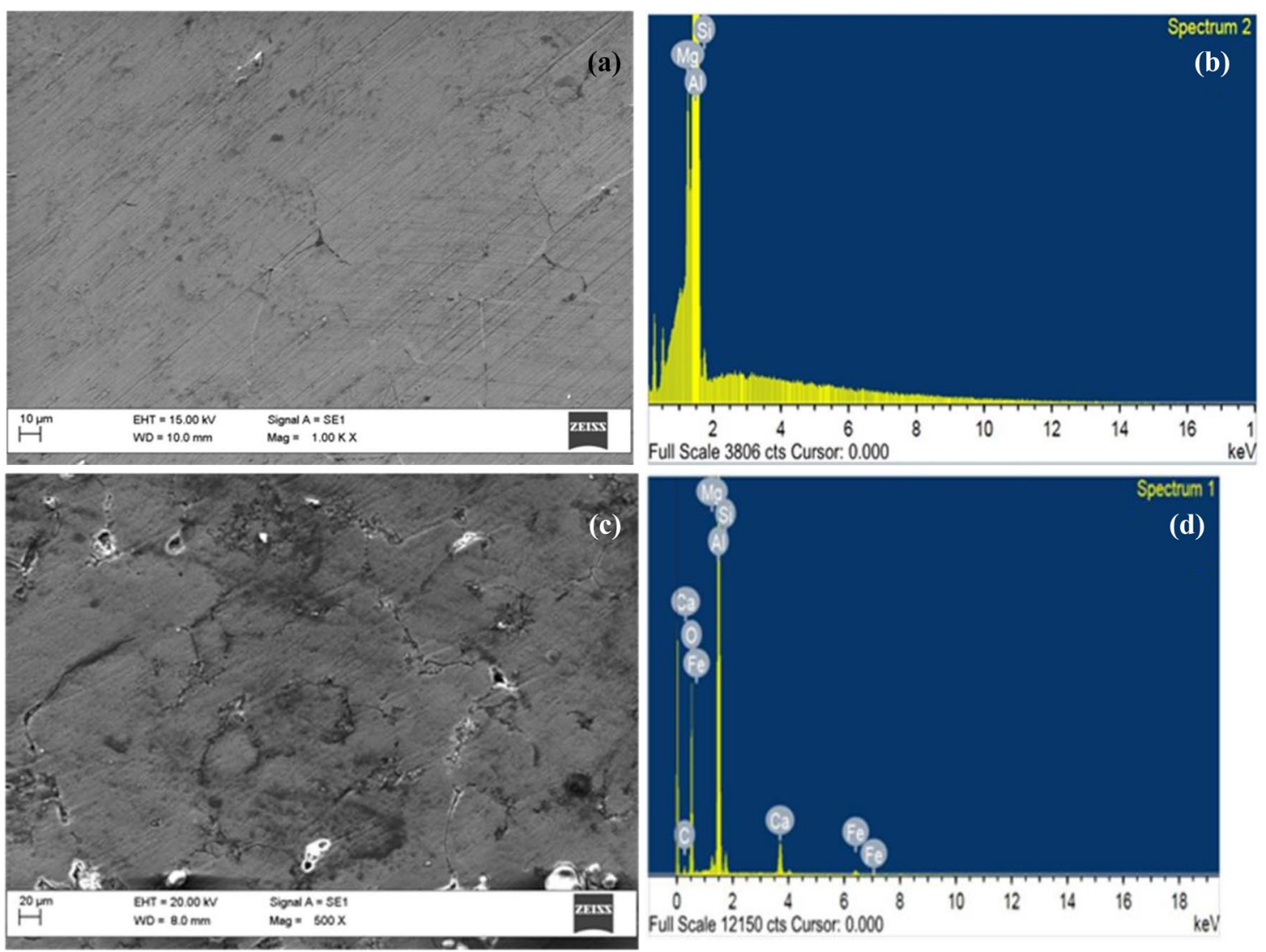

Fig. 3 a SEM image and $\mathbf{b}$ EDX of Al6061 alloy c SEM image and d EDX of 8 wt\% composite 

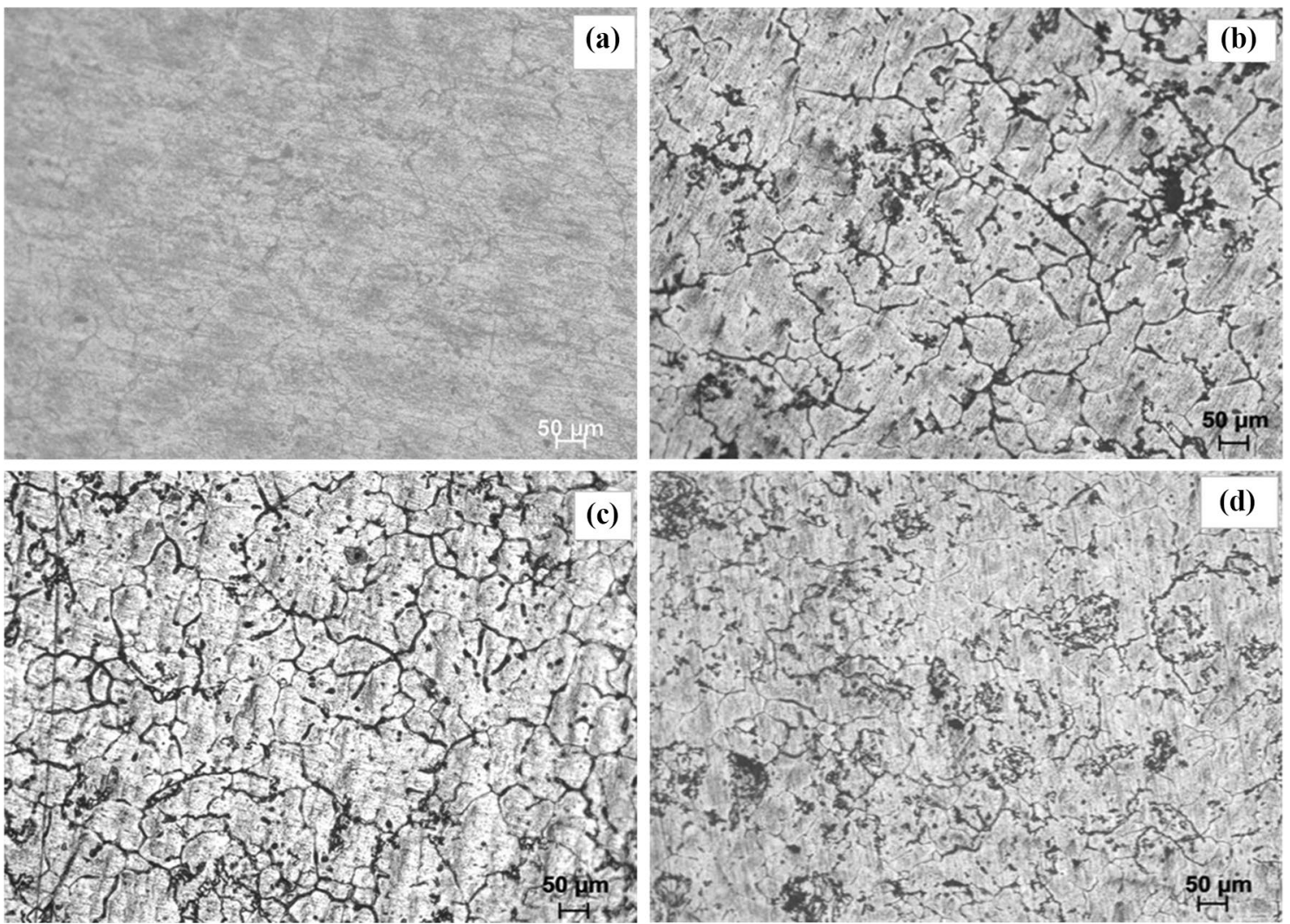

Fig. 4 Optical micrographs of a unreinforced as-cast Al6061 alloy and reinforced composite with b 2 wt $\%$ MS, c 6 wt $\%$ MS and d 10 wt $\%$ MS particles

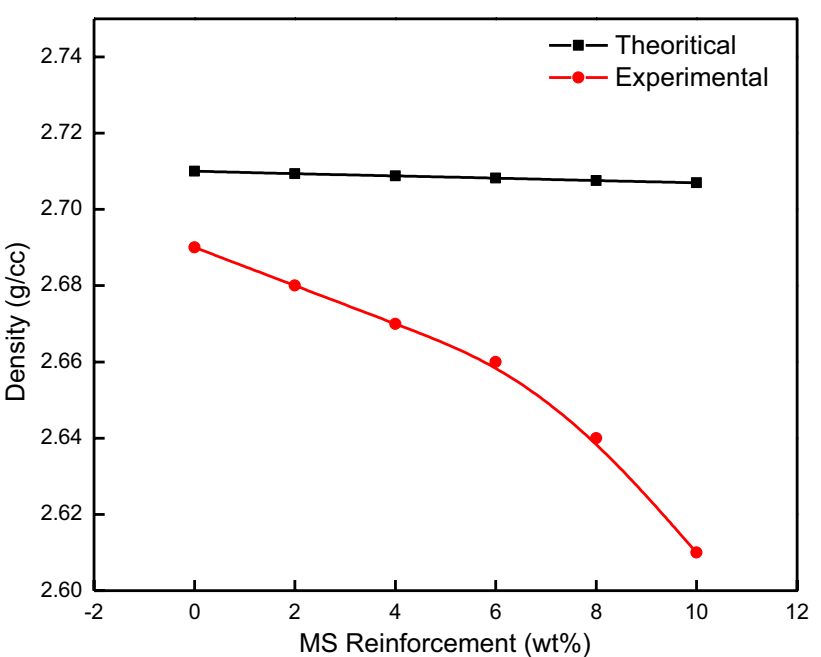

Fig. 5 Variation of the density of composites with MS reinforcement weight percentage

\subsection{Hardness}

Figure 6 describes the variation of the hardness of all composites including unreinforced alloy. It is evident

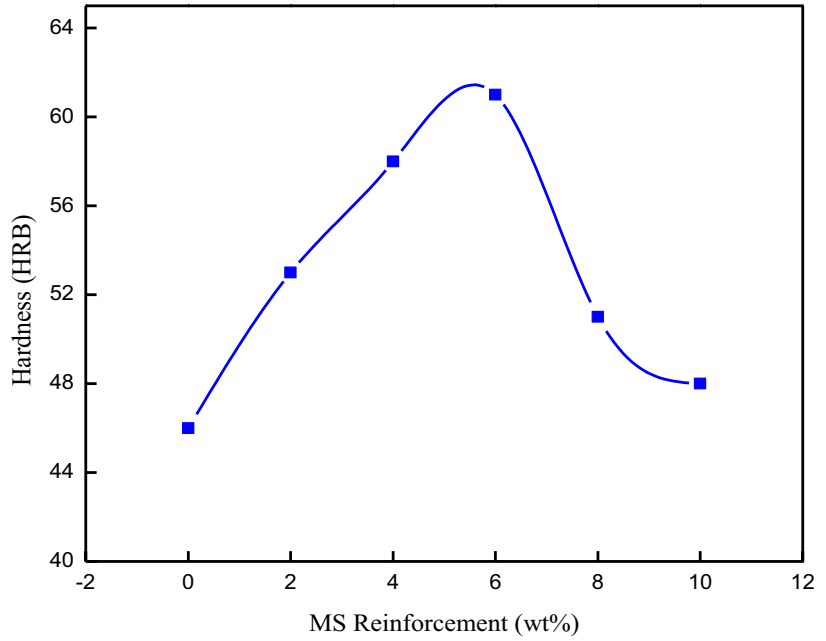

Fig. 6 Variation of Hardness of composites with MS reinforcement weight percentage

from the figure that the addition of reinforcement in different weight fraction exercised increase in the hardness of the alloy matrix. Such enhancement can be pointed to the hard and brittle nature of MS particles and its attendance in the matrix upgraded the hardness 
of the composite $[30,31]$. It is reported that the presence $\mathrm{SiO}_{2}$ in the reinforcing ceramics, mixed evenly within the composite and contributes towards the hardness increase [32]. Also, the presence of hard and brittle particles in the melt causes an increase in dislocation density during solidification, mainly due to the mismatch of thermal properties of the matrix and reinforcing particles [33, 34]. Sharma et al. [35] have shown that thermal mismatch conditions during solidification cause large plastic deformation of the matrix for compensating smaller volume expansion of ceramic reinforcement. This difference appreciably develops a region of large internal stresses, resulting in an increase in hardness. It has also been experienced that 6 wt $\%$ composite contained maximum particle filling content and exhibited the highest hardness among all composites. After $6 \mathrm{wt} \%$ MS particles, further addition of particles impaired with a decrease in hardness. The further addition of particles caused the viscosity of the melt, leads to an increase in porosity.

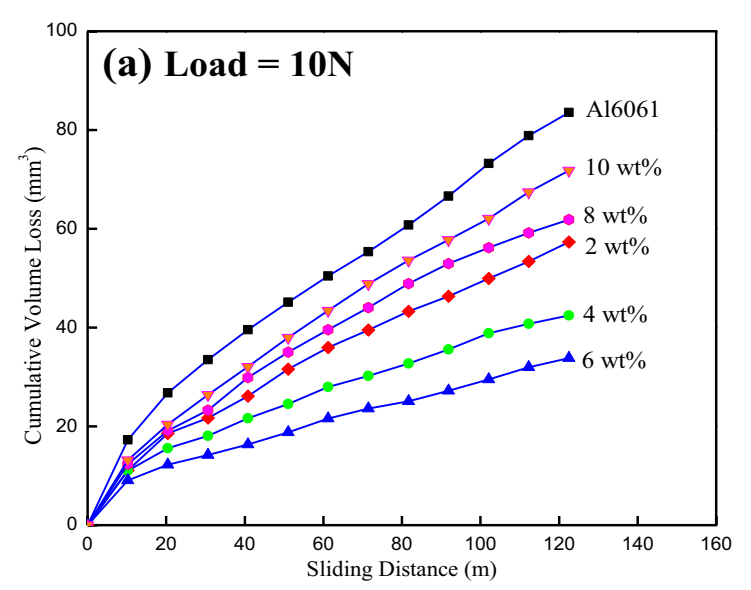

\subsection{Wear analysis}

Dry sliding wear tests were performed at constant sliding velocity $(\mathrm{V}=1.02 \mathrm{~m} / \mathrm{s})$ at three different loads against the fixed sliding distance of $122 \mathrm{~m}$. The variation of cumulative volume loss against sliding distance for various composites at different loads of $10 \mathrm{~N}, 20 \mathrm{~N}$ and $30 \mathrm{~N}$ has been revealed in Fig. 7 . It is found that at a given load, volume loss increases with an increase in sliding distance for both unreinforced alloy matrix and composites. It is attributed to the increase in temperature of the pin surfaces when undergoing frictional sliding motion against the counter surface and remaining in contact for larger sliding distance [36]. This causes the surface softening of both the matrix alloy and composites which results in a higher volumetric loss. The volumetric loss of all composites is noted to be lower than that of the matrix alloy, being lowest for 6 wt $\%$ composite. Clearly, the hardness improvement due to particle incorporation in the matrix plays an important role in decreasing the wear loss. It is evident from previous work that wear and seizure resistance of materials can

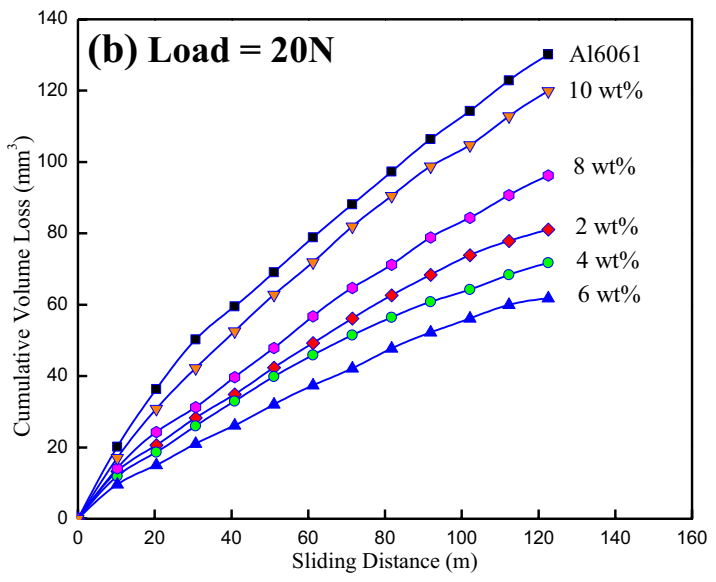

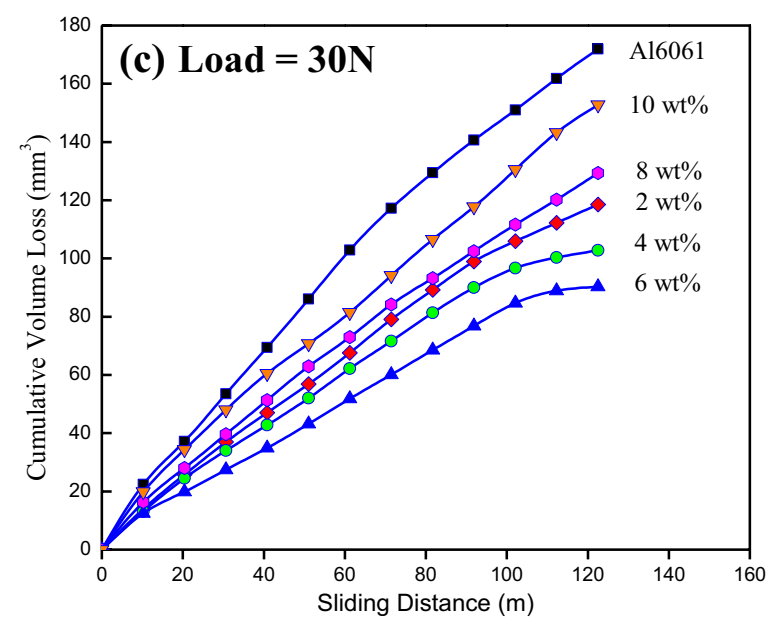

Fig. 7 Variation of volumetric wear loss of composites with Sliding distance at a $10 \mathrm{~N}, \mathbf{b} 20 \mathrm{~N}$ and c $30 \mathrm{~N}$ load 


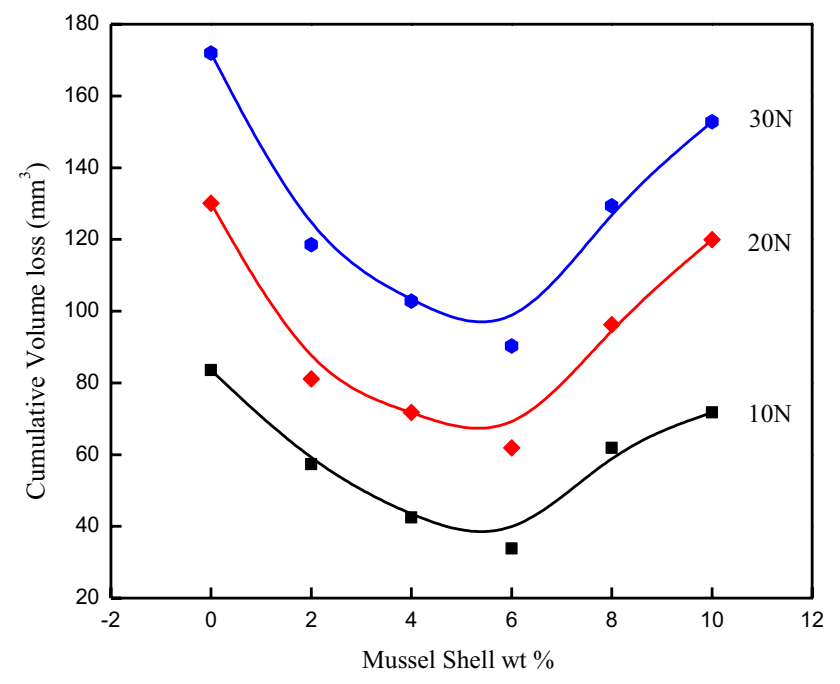

Fig. 8 Variation of volumetric wear loss with wt\% of mussel shell reinforcement at different loads after sliding distance of $122 \mathrm{~m}$ be improved by enhancing the hardness of the material [37-39].

It is evident from Fig. 8 that volumetric wear loss increased considerably with increase in load for both matrix alloy and composites. It is important to note that the smearing effect of counter $\mathrm{SiC}$ particles on the soft matrix surface, carrying out easy delamination and plowing of the matrix while sliding. At low loads, the wear surfaces are reflected with fine scratches while it transformed to deeper grooves when the load is increased. However, at all the studied loads, composites exhibited lower volumetric loss compared to matrix alloy and $6 \mathrm{wt} \%$ composites recorded the lowest loss. Improvement in the hardness of composites due to the incorporation of hard ceramic particles is cited as the reason for improved wear resistance [40-42].

Figure 9 illustrates the variation of wear rate of matrix alloy and composites with sliding distance at different

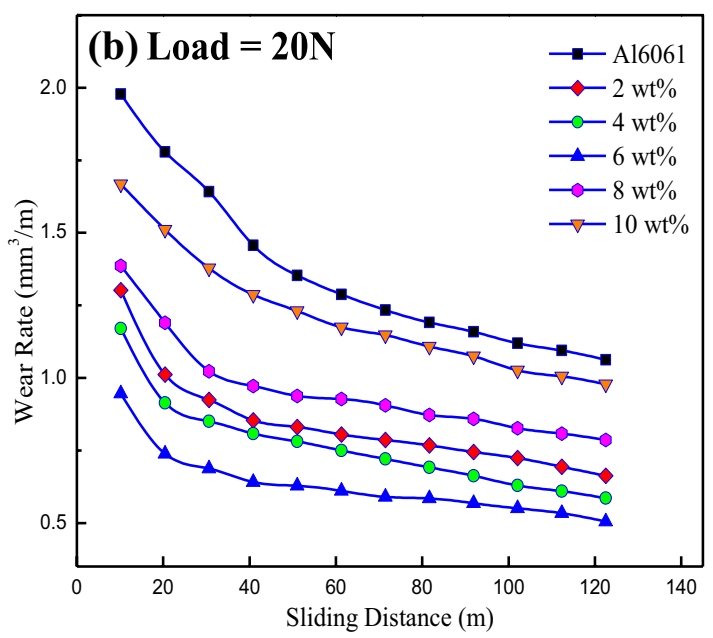

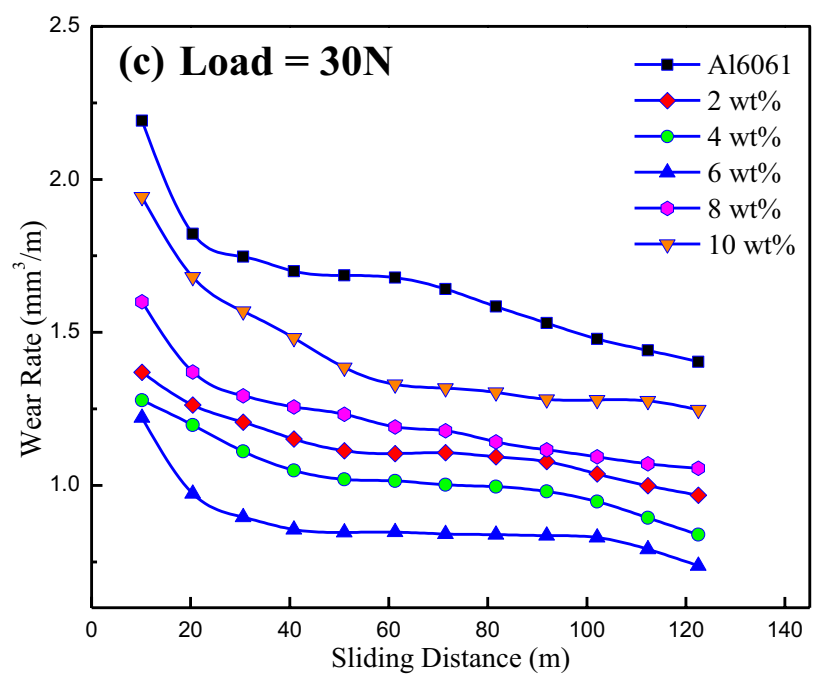

Fig. 9 Variation of wear rate of composites with Sliding distance at a $10 \mathrm{~N}, \mathbf{b} 20 \mathrm{~N}$ and c $30 \mathrm{~N}$ load 
loads. At all load studied, the computed wear rate is very high for both alloy and composite during the early stage of sliding. The softer matrix when comes in contact with the fresh and sharp-edged abrasive SiC particles of emery paper, it allows easy penetrating effect and material removal from soft material under relative motion. However, in a later stage, the wear rate diminishes sharply and follows a steady variation due to the likes of factors mainly the work hardening effect, formation of protective layer and presence of wear debris. Srivastava and Das [43] discussed the effect of work hardening on a reduced wear rate of metal matrix composite. It is reported that the work-hardened surface is formed on the top surface and sub-surface regions of the ductile matrix during sliding, leads to a reduction in the wear rate of composite. It has been reported in the literature that development of mechanically mixed layer (MML) on the sliding surface of the pin sample, protects and shields the material from further wear $[7,44]$. Wear debris produced during sliding motion, are loose and free to slide or roll between two surfaces and thus, hinder the two-body contact mechanism. Existence of such scenarios, altogether greatly diminishes the wear rate of material [45]. The wear resistance of all composites is recorded to be much higher than that of the matrix alloy. Improvement in hardness and load-bearing capacity of composites due to the presence of hard reinforcement is reasoned for such cause.

\subsection{Coefficient of friction analysis}

Variation of the coefficient of friction of alloy and different composites against sliding distance at different loads has been shown in Fig. 10. At a given load, the coefficient of friction of composites is lower than the alloy matrix, $6 \mathrm{wt} \%$ composite recorded the lowest coefficient. It is marked to the hardness improvement of the composite
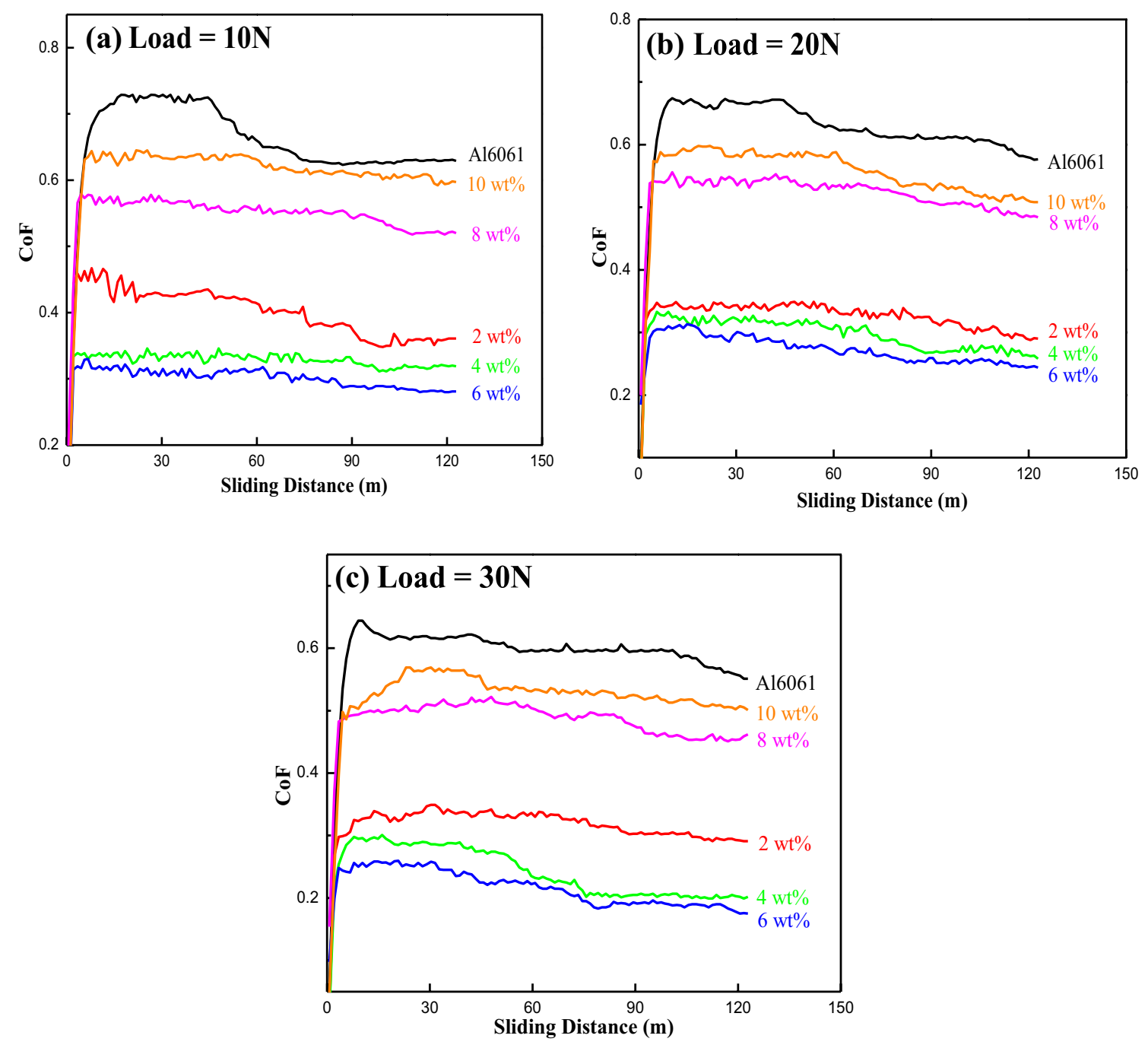

Fig. 10 Variation of friction coefficient of composites with Sliding distance at a $10 \mathrm{~N} \mathrm{~b} 20 \mathrm{~N}$ and c $30 \mathrm{~N}$ load 
which offered the lowest resistance to the motion due to less smearing effect of abrasive $\mathrm{SiC}$ particles on the matrix material. It is confirmed by Mondal et al. [46] that sticking tendency of hard surfaces with the counter surface during sliding reduces significantly compared to soft surfaces. Alloy registered the highest coefficient due to a high degree of softness of the matrix, allowing easy penetration of abrasives and a hindered sliding motion. It is also noticed that CoF in the later stages decreased for all composites. Pointing out the hardening effect of the matrix, bluntness of the sharp edges of abrasive particles and presence of increased wear debris, thus converting
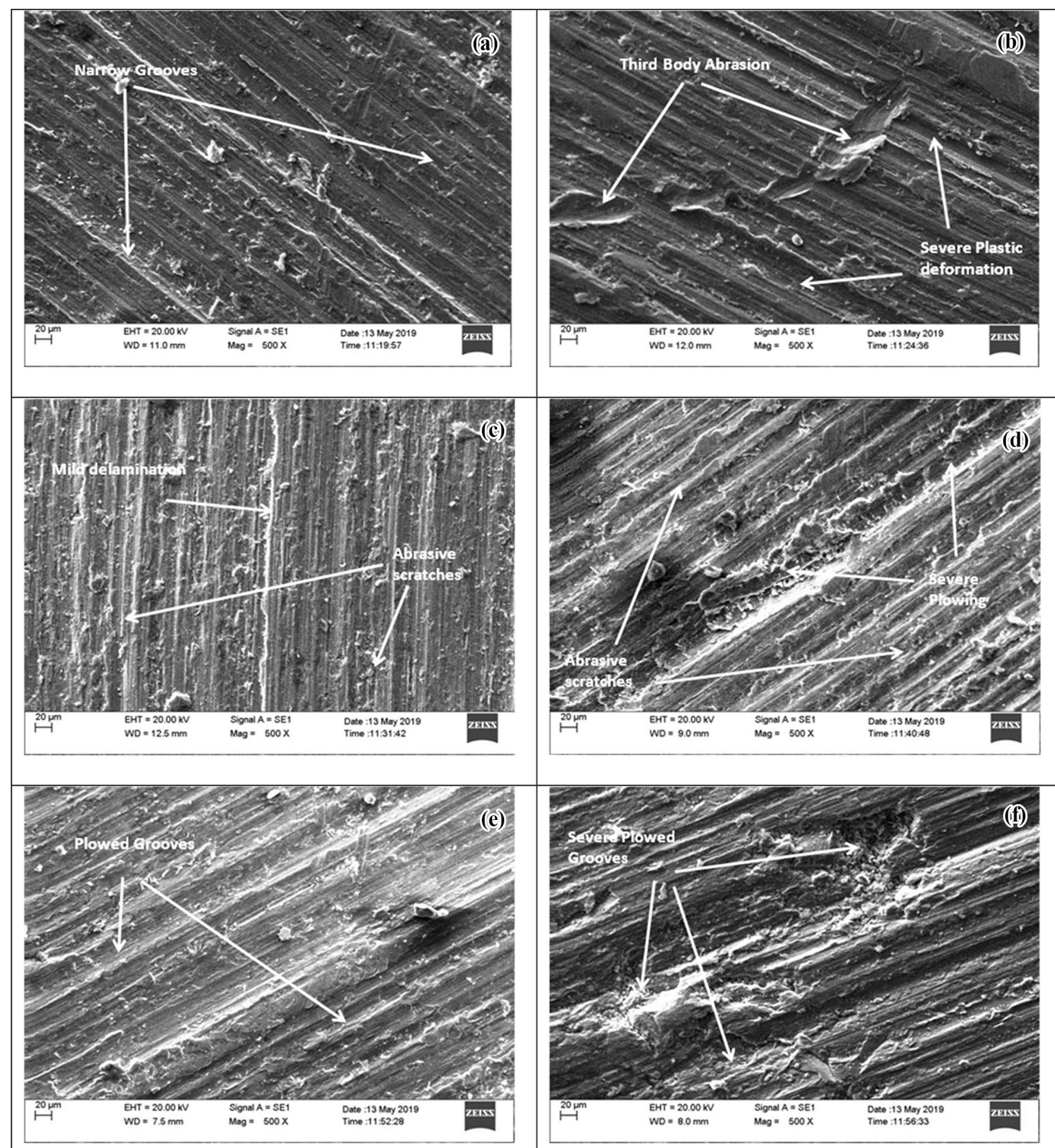

Fig. 11 SEM images of worn surface of a 2 wt $\%$ composite at $10 \mathrm{~N}, \mathbf{b} 2 \mathrm{wt} \%$ composite at $30 \mathrm{~N}, \mathbf{c} 6$ wt $\%$ composite at $10 \mathrm{~N}, \mathbf{d} 6 \mathrm{wt} \%$ composite at $30 \mathrm{~N}, \mathbf{e} 10 \mathrm{wt} \%$ composite at $10 \mathrm{~N}$ and $\mathbf{f} 10 \mathrm{wt} \%$ composite at $30 \mathrm{~N}$ 
two-body to three-body abrasion and undergoing sliding or rolling motion with minimum resistance offered, collectively retarded the friction coefficient at higher sliding distances. It is also observed that CoF has decreased with increase in load for alloy and all composites. Increase in load caused more wear of sample pin, suggesting easy material removal from the surface. It shows that resistance to motion stays active for very less time and therefore, $\mathrm{CoF}$ is recorded to be less at higher load.

Figure 11 illustrates the SEM micrographs of worn surfaces of different composites at a load of $10 \mathrm{~N}$ and $30 \mathrm{~N}$. It is noticed that the degree of plastic deformation increases with increase in load. The morphology of grooves changes from narrow to deep and wide, suggesting severe plowing effect and larger volumetric wear loss. This is well evident in Fig. $11 \mathrm{a}$ and $\mathrm{b}$, belonging to $2 \mathrm{wt} \%$ composite. From Fig. 11c and d, it is realized that $6 \mathrm{wt} \%$ composite offered good wear resistance and with an increase in load, mild delamination effect is observed apart from mild abrasive scratches at low load. This suggests the characteristics of hard surface attained by $6 \mathrm{wt} \%$ composite due to the incorporation of hard ceramic reinforcement and loadbearing capacity of the surface. Further $10 \mathrm{wt} \%$ composite demonstrated poor wear resistance as suggested by the morphology of wear surfaces, shown in Fig. 11e and f, illustrating the presence of plowed grooves and delaminated layers on surfaces. The severity of plastic deformation increased with increase in load supported by wider and deeper grooves.

\subsection{Regression analysis}

Wear performance was measured as a function of controlling parameters load, sliding distance and reinforcement $w t \%$. Although, experiments showed that reinforcement of matrix with hard ceramic particles improved the wear resistance of fabricated composite individually but combined effect of the parameters on wear performance cannot be recognized easily from the graphs plotted. Therefore, a statistical analysis is carried out to mention the order of merit affecting the wear response whether significantly. The collected data is used to develop an empirical relation for wear responses, cumulative volume loss $(\mathrm{V})$ and wear rate $(\mathrm{W})$, as a function of load (L), sliding distance $(\mathrm{S})$ and reinforcement wt\% $(\mathrm{R})$, through Linear multiple regression analysis which is as follows:

$$
\begin{aligned}
V & =-48.84+2.240 L+0.6117 S+2.760 R \\
W & =0.2370+0.02746 L-0.002399 S+0.03509 R
\end{aligned}
$$

In the above equation, the positive output shows increased response and vice versa. Further, the positive sign of coefficients associated with the control factors
$(\mathrm{L}, \mathrm{S}$, and $\mathrm{R})$ indicates that the wear loss and wear rate increases while the magnitude represents the weight of the factors. Clearly, volumetric loss increases with an increase in load, sliding distance and reinforcement in contrast. It is due to the fact that alloy showed the maximum filling capability of 6 wt\% of MS, post to that the viscosity increased considerably and proved detrimental. Similarly, wear rate increased with load, reinforcement but decreased with sliding distance as suggested by the negative coefficient, reasons for which has already been mentioned.

ANOVA helps in predicting the significance of variables on the dependent response, based on fisher's value (F). ANOVA analysis for both wear responses are shown in Tables 2 and 3. Clearly, all the control factors are significantly affecting the wear response as suggested by $F$-value for each factor which is above the critical value $(F>4)$ [47]. Also, F-value indicates that wear loss and wear rate is most affected by sliding distance and load respectively, which recorded a higher value of $F$ against the response.

The correlation coefficient for volumetric loss and wear rate is recorded as 81.25 and 77.89 respectively. The output of developed models was further authenticated by comparing the result with experimental values for the same set of independent factors. Table 4 presents the comparison result and it is found that models are in sound agreement with experimental values within the appreciable deviation percentage range of -5 to $12 \%$.

Table 2 ANOVA for volumetric wear loss (V)

\begin{tabular}{lrrrrr}
\hline Source & DF & Adj SS & Adj MS & F-value & $p$ value \\
\hline Regression & 3 & 36,216 & $12,072.1$ & 59.23 & 0.000 \\
L & 1 & 15,059 & $15,059.0$ & 73.88 & 0.000 \\
S & 1 & 18,415 & $18,414.9$ & 90.35 & 0.000 \\
R & 1 & 2742 & 2742.4 & 13.45 & 0.001 \\
Error & 41 & 8357 & 203.8 & & \\
Total & 44 & 44,573 & & & \\
\hline
\end{tabular}

Table 3 ANOVA for wear rate (W)

\begin{tabular}{lrrrrr}
\hline Source & DF & Adj SS & Adj MS & F-value & $p$ value \\
\hline Regression & 3 & 2.9891 & 0.99637 & 48.15 & 0.000 \\
L & 1 & 2.2626 & 2.26264 & 109.35 & 0.000 \\
S & 1 & 0.2833 & 0.28328 & 13.69 & 0.001 \\
R & 1 & 0.4432 & 0.44317 & 21.42 & 0.000 \\
Error & 41 & 0.8484 & 0.02069 & & \\
Total & 44 & 3.8375 & & & \\
\hline
\end{tabular}


Table 4 Confirmation test

\begin{tabular}{llllllllll}
\hline Exp. no. & Load (N) & $\begin{array}{l}\text { Sliding } \\
\text { Distance } \\
(\mathrm{m})\end{array}$ & $\begin{array}{l}\text { Reinforce- } \\
\text { ment } \\
(\mathrm{wt} \%)\end{array}$ & $\begin{array}{l}\text { Volume loss } \\
\text { (exp.) }\end{array}$ & $\begin{array}{l}\text { Volume } \\
\text { loss } \\
\text { (model) }\end{array}$ & $\begin{array}{l}\text { Deviation (\%) } \\
\text { between exp. } \\
\text { and model }\end{array}$ & $\begin{array}{l}\text { Wear Rate } \\
\text { (exp.) }\end{array}$ & $\begin{array}{l}\text { Wear rate } \\
\text { (model) }\end{array}$ & $\begin{array}{l}\text { Deviation (\%) } \\
\text { between exp. } \\
\text { and model }\end{array}$ \\
\hline 1 & 10 & 122 & 10 & 75.787 & 71.794 & 5.26 & 0.5698 & 0.5859 & -2.83 \\
2 & 20 & 122 & 4 & 81.627 & 71.772 & 12.07 & 0.6338 & 0.5857 & 7.58 \\
3 & 20 & 122 & 8 & 92.667 & 96.276 & -3.89 & 0.7742 & 0.7857 & -1.49 \\
4 & 30 & 122 & 4 & 104.027 & 102.756 & 1.22 & 0.9084 & 0.8386 & 7.683 \\
5 & 30 & 80 & 4 & 78.336 & 81.321 & -3.81 & 1.0092 & 0.9956 & 1.35 \\
6 & 30 & 80 & 8 & 89.376 & 93.283 & -4.37 & 1.1496 & 1.1420 & 0.65 \\
\hline
\end{tabular}

\section{Conclusion}

In the Present work, a sincere effort has been made to quantify the engineering aspects of a bio-waste mussel shell. Based on the experimental work the following major conclusions have been drawn:

- Mussel Shell particles are successfully incorporated as reinforcement for the fabrication of Al6061/MS metal matrix composite via stir casting process.

- Optical micrographs revealed that particles are fairly distributed in the matrix with 6 wt\% composite publicized the maximum MS particle filling capacity. Increase in reinforcement highlighted the porosity factor in dominance thereafter.

- Incorporation of MS particulates increased the overall hardness and wear resistance of composites while $6 \mathrm{wt} \%$ composite demonstrated the best properties. Increase in hardness is attributed to differences in thermal properties of reinforcement and matrix phase whose mismatch results in an increase of dislocation densities during solidification.

- Coefficient of friction of composites decreased with an increase in load and sliding distance. Wear surface study elaborated that wear mechanism shifted from mild to severe delamination with an increase in load, best resisted by $6 \mathrm{wt} \%$ composites.

- Regression model developed for wear outputs were in good agreement with experimental results. ANOVA confirmed that mussel shell reinforcement has significantly improved the wear properties of matrix Al6061.

\section{Compliance with ethical standards}

Conflict of interest The authors declare that they have no competing interests.

\section{References}

1. Miracle DB (2005) Metal matrix composites: from science to technological significance. Compos Sci Technol 65:2526-2540. https://doi.org/10.1016/j.compscitech.2005.05.027

2. Kaczmar JW, Pietrzak K, Wlosinski W (2000) The production and application of metal matrix composite materials. J Mater Process Technol 106:58-67. https://doi.org/10.1016/S0924 -0136(00)00639-7

3. Martın A, Llorca J, Rodrıguez J (1999) Temperature effects on the wear behavior of particulate reinforced Al-based composites. Wear 225:615-620

4. Radha A, Vijayakumar KR (2016) ScienceDirect An investigation of mechanical and wear properties of AA6061 reinforced with silicon carbide and graphene nano particles: particulate composites. Mater Today Proc 3:2247-2253. https://doi. org/10.1016/j.matpr.2016.04.133

5. Pazhouhanfar Y, Eghbali B (2018) Microstructural characterization and mechanical properties of $\mathrm{TiB}_{2}$ reinforced $\mathrm{Al} 6061$ matrix composites produced using stir casting process. Mater Sci Eng A 710:172-180. https://doi.org/10.1016/j.msea.2017.10.087

6. Ravi B, Naik BB, Prakash JU (2015) Characterization of aluminium matrix composites (AA6061/B $\mathrm{B}_{4}$ ) fabricated by stir casting technique. Mater Today Proc 2:2984-2990. https://doi.org/10.1016/j. matpr.2015.07.282

7. Manivannan I, Ranganathan S, Gopalakannan S, Suresh S (2018) Mechanical properties and tribological behavior of Al6061-SiCGr self-lubricating hybrid nanocomposites. Trans Indian Inst Met 71:1897-1911. https://doi.org/10.1007/s12666-018-1321-0

8. Li B, Luo B, He K, Fan W (2016) Effect of Mg on nucleation process of recrystallization in $\mathrm{Al}-\mathrm{Mg}-\mathrm{Si} / \mathrm{SiC} \mathrm{p}$ composite. Trans Nonferrous Met Soc China 26:2561-2566. https://doi.org/10.1016/ S1003-6326(16)64382-0

9. Sankara Raju RS, Panigrahi MK, Ganguly RI, Srinivasa Rao G (2019) Tribological behaviour of Al-1100-coconut shell ash (CSA) composite at elevated temperature. Tribol Int 129:55-66. https ://doi.org/10.1016/j.triboint.2018.08.011

10. Dwivedi SP, Sharma S, Mishra RK (2016) Characterization of waste eggshells and $\mathrm{CaCO}_{3}$ reinforced AA2014 green metal matrix composites: a green approach in the synthesis of composites. Int J Precis Eng Manuf 17:1383-1393. https://doi. org/10.1007/s12541-016-0164-z

11. Alaneme KK, Adewale TM, Olubambi PA (2014) Corrosion and wear behaviour of Al-Mg-Si alloy matrix hybrid composites reinforced with rice husk ash and silicon carbide. J Mater Res Technol 3:9-16. https://doi.org/10.1016/j.jmrt.2013.10.008

12. Senapati A, Srivastava S, Ghadai A, Kumar R, Kujur A (2014) Effect of reinforcement on abrasive wear of different aluminium 
based metal matrix composite-a review. Int J Eng Trends Technol 8:240-245

13. Dinaharan I, Nelson R, Vijay SJ, Akinlabi ET (2016) Microstructure and wear characterization of aluminum matrix composites reinforced with industrial waste fly ash particulates synthesized by friction stir processing. Mater Charact 118:149-158. https://doi. org/10.1016/j.matchar.2016.05.017

14. Dwiwedi SK, Srivastava AK, Sugimoto K, Chopkar M (2018) Microstructural and mechanical characterization of chicken eggshell-reinforced Al6061 matrix composites. Open J Met. https://doi.org/10.4236/ojmetal.2018.81001

15. Sharma S, Dwivedi SP (2017) Effects of waste eggshells and SiC addition on specific strength and thermal expansion of hybrid green metal matrix composite. J Hazard Mater. https://doi. org/10.1016/j.jhazmat.2017.01.002

16. Ma Y, Chai X, Yan Z, Chen D, Man J (2012) Clam shell compression characteristics and bond strength. Adv Mater Res 475:2554-2557. https://doi.org/10.4028/www.scientific.net/ AMR.472-475.2554

17. Oladele IO, Olajide JL, Amujede M (2016) Wear resistance and mechanical behaviour of epoxy/mollusk shell biocomposites developed for structural applications. Tribol Ind 38:347-360

18. Kumar GS, Girija EK, Venkatesh M, Karunakaran G, Kolesnikov E, Kuznetsov D (2017) One step method to synthesize flowerlike hydroxyapatite architecture using mussel shell bio-waste as a calcium source. Ceram Int 43:3457-3461. https://doi. org/10.1016/j.ceramint.2016.11.163

19. Shavandi A, Bekhit AEA, Ali MA, Sun Z (2015) Bio-mimetic composite scaffold from mussel shells, squid pen and crab chitosan for bone tissue engineering. Int J Biol Macromol 80:445-454. https://doi.org/10.1016/j.ijbiomac.2015.07.012

20. Li M, Yao ZT, Chen T, Lou ZH, Xia M (2014) The antibacterial activity and mechanism of mussel shell waste derived material. Powder Technol 264:577-582. https://doi.org/10.1016/j.powte c.2014.05.067

21. Xiong J, Qin Y, Islam E, Yue M, Wang W (2011) Phosphate removal from solution using powdered freshwater mussel shells. DES 276:317-321. https://doi.org/10.1016/j.desal.2011.03.066

22. Hu S, Wang Y, Han H (2011) Utilization of waste freshwater mussel shell as an economic catalyst for biodiesel production. Biomass Bioenerg 35:3627-3635. https://doi.org/10.1016/j.biomb ioe.2011.05.009

23. Ez-zaki H, El Gharbi B, Diouri A (2018) Development of ecofriendly mortars incorporating glass and shell powders. Constr Build Mater 159:198-204. https://doi.org/10.1016/j.conbuildma t.2017.10.125

24. Lv J, Jiang Y, Zhang D (2015) Structural and mechanical characterization of Atrina pectinata and freshwater mussel shells. J Bionic Eng 12:276-284. https://doi.org/10.1016/S1672 $-6529(14) 60120-7$

25. Martínez-garcía C, González-fonteboa B, Martínez-abella F, López DC (2017) Virtual special issue bio based building materials performance of mussel shell as aggregate in plain concrete. Constr Build Mater 139:570-583. https://doi.org/10.1016/j. conbuildmat.2016.09.091

26. Martínez-García C, González-Fonteboa B, Carro-López D, Martínez-Abella F (2019) Impact of mussel shell aggregates on air lime mortars. Pore structure and carbonation. J Clean Prod 215:650-668. https://doi.org/10.1016/j.jclepro.2019.01.121

27. Manivannan I, Ranganathan S, Gopalakannan S, Suresh S, Nagakarthigan K, Jubendradass R (2017) Tribological and surface behavior of silicon carbide reinforced aluminum matrix nanocomposite. Surf Interfaces 8:127-136. https://doi.org/10.1016/j. surfin.2017.05.007

28. Akbari MK, Baharvandi HR, Mirzaee O (2013) Nano-sized aluminum oxide reinforced commercial casting A356 alloy matrix: evaluation of hardness, wear resistance and compressive strength focusing on particle distribution in aluminum matrix. Compos Part B Eng 52:262-268. https://doi. org/10.1016/j.compositesb.2013.04.038

29. Ramnath BV, Elanchezhian C, Atreya TSA, Vignesh V (2014) Aluminum metal matrix composites: a review. Rev Adv Mater Sci 38:55-60

30. Kumar GBV, Rao CSP, Selvaraj N (2012) Composites: part B studies on mechanical and dry sliding wear of Al6061SiC composites. Compos Part B 43:1185-1191. https://doi. org/10.1016/j.compositesb.2011.08.046

31. Rajan TPD, Pillai RM, Pai BC, Satyanarayana KG, Rohatgi PK (2007) Fabrication and characterisation of Al-7Si-0.35 Mg/ fly ash metal matrix composites processed by different stir casting routes. Compos Sci Technol 67:3369-3377. https://doi. org/10.1016/j.compscitech.2007.03.028

32. Prakash KS, Kanagaraj A, Gopal PM (2015) Dry sliding wear characterization of Al 6061/rock dust composite. Trans Nonferrous Met Soc China 25:3893-3903. https://doi.org/10.1016/ S1003-6326(15)64036-5

33. Lancaster L, Lung MH, Sujan D (2013) Utilization of agro-industrial waste in metal matrix composites: towards sustainability. Int J Environ Chem Ecol Geol Geophys Eng 7(1):35-43

34. Hassan SB, Aigbodion VS (2015) Effects of eggshell on the microstructures and properties of $\mathrm{Al}-\mathrm{Cu}-\mathrm{Mg} /$ eggshell particulate composites. J King Saud Univ Eng Sci 27:49-56. https ://doi.org/10.1016/j.jksues.2013.03.001

35. Sharma P, Khanduja D, Sharma S (2015) Parametric study of dry sliding wear of aluminium metal matrix composites by response surface methodology. Mater Today Proc 2:26872697. https://doi.org/10.1016/j.matpr.2015.07.234

36. Qin QD, Zhao YG, Zhou W (2008) Dry sliding wear behavior of $\mathrm{Mg}_{2} \mathrm{Si} / \mathrm{Al}$ composites against automobile friction material. Wear 264:654-661. https://doi.org/10.1016/j.wear.2007.05.008

37. Ramesh CS, Khan ARA, Ravikumar N, Savanprabhu P (2005) Prediction of wear coefficient of Al6061- $\mathrm{TiO}_{2}$ composites. Wear 259:602-608. https://doi.org/10.1016/j.wear.2005.02.115

38. Suresh S, Shenbaga Vinayaga Moorthi N, Vettivel SC, Selvakumar N (2014) Mechanical behavior and wear prediction of stir cast $\mathrm{Al}-\mathrm{TiB}_{2}$ composites using response surface methodology. Mater Des 59:383-396. https://doi.org/10.1016/j.matde s.2014.02.053

39. Dwiwedi SK, Srivastava AK, Chopkar MK (2019) Wear study of chicken eggshell-reinforced Al6061 matrix composites. Trans Indian Inst Met 72:73-84. https://doi.org/10.1007/s1266 6-018-1463-0

40. Straffelini G, Bonollo F, Molinari A, Tiziani A (1997) Influence of matrix hardness on the dry sliding behaviour of 20 vol.\% $\mathrm{Al}_{2} \mathrm{O}_{3}$-particulate-reinforced $6061 \mathrm{Al}$ metal matrix composite. Wear 211:192-197. https://doi.org/10.1016/s0043 -1648(97)00119-1

41. Kingsly JA, Dinaharan I, Sheriff NM, Raja JD (2017) Journal of asian ceramic societies dry sliding wear behavior of AA6061 aluminum alloy composites reinforced rice husk ash particulates produced using compocasting. Integr Med Res 5:127-135. https ://doi.org/10.1016/j.jascer.2017.03.005

42. Sharma P, Paliwal K, Kumar R, Sharma S (2017) Journal of asian ceramic societies a study on wear behaviour of $\mathrm{Al} / 6101 /$ graphite composites. Integr Med Res 5:42-48. https://doi.org/10.1016/j. jascer.2016.12.007

43. Srivastava AK, Das K (2010) The abrasive wear resistance of TIC and (Ti, W) C-reinforced Fe-17Mn austenitic steel matrix composites. Tribiol Int 43:944-950. https://doi.org/10.1016/j.tribo int.2009.12.057

44. Rao RN, Das S (2010) Effect of matrix alloy and influence of SiC particle on the sliding wear characteristics of aluminium alloy 
composites. Mater Des 31:1200-1207. https://doi.org/10.1016/j. matdes.2009.09.032

45. Alpas AT, Bhattacharya S (2018) Wear of particulate metal matrix composites, vol 4. Elsevier, Amsterdam. https://doi.org/10.1016/ b978-0-12-803581-8.09965-3

46. Mondal DP, Das S, Rao RN, Singh M (2005) Effect of SiC addition and running-in-wear on the sliding wear behaviour of $\mathrm{Al}-\mathrm{Zn}-$ Mg aluminium alloy. Mater Sci Eng 402:307-319. https://doi. org/10.1016/j.msea.2005.05.023

47. Thankachan T, Prakash KS (2017) Microstructural, mechanical and tribological behavior of aluminum nitride reinforced copper surface composites fabricated through friction stir processing route. Mater Sci Eng A 688:301-308. https://doi.org/10.1016/j. msea.2017.02.010

Publisher's Note Springer Nature remains neutral with regard to jurisdictional claims in published maps and institutional affiliations. 